\title{
Adenoviral-expressed $\mathrm{GP}_{5}$ of porcine respiratory and reproductive syndrome virus differs in its cellular maturation from the authentic viral protein but maintains known biological functions
}

\author{
C. A. Gagnon ${ }^{1,2}$, G. Lachapelle ${ }^{1,2}$, Y. Langelier ${ }^{3,4}$, B. Massie ${ }^{1,2,4}$, \\ and S. Dea ${ }^{1, *}$ \\ ${ }^{1}$ INRS-Institut Armand-Frappier, Laval, Canada \\ ${ }^{2}$ Biotechnology Research Institute, CNRC, Montreal, Canada \\ ${ }^{3}$ Centre de Recherche du Centre Hospitalier de l'Université de Montréal, Hôpital \\ Notre-Dame, Montréal, Canada \\ ${ }^{4}$ Département de Microbiologie et Immunologie, Faculté de Médecine, Université de \\ Montréal, Montréal, Canada
}

Received April 8, 2002; accepted October 15, 2002

Published online March 3, 2003 (C) Springer-Verlag 2003

Summary. The ORFs 5, 6 and 7, encoding for the three major structural proteins, $\mathrm{GP}_{5}, \mathrm{M}$ and N, of the IAF-Klop strain of PRRSV were cloned and expressed in 293 cells using replication-defective human type 5 adenoviral vectors (hAdVs). Although the M protein gene could be cloned into hAdVs and expressed constituvely in 293 cells under the control of the hCMV immediate early promotor/enhancer, hAdVs expressing $\mathrm{N}$ and $\mathrm{GP}_{5}$ proteins, which appeared to be toxic or interfered with adenovirus replication, could only be generated by inclusion of a tetracycline-regulatable promotor in the transfer vector pAdTR5. The recombinant (rec) proteins appeared similar to the authentic viral proteins in regards to their $M_{\mathrm{r}} \mathrm{s}$ and antigenicities. However, the recGP 5 apparently possesses different $\mathrm{N}-$ linked oligosaccharides residues. Its sensitivity to endo- $\beta$-galactosidase digestion indicates that poly- $\mathrm{N}$-acetyllactosamine is present on the individually-expressed protein, but not on the authentic $\mathrm{GP}_{5}$ anchored into the virion envelope. The rec $\mathrm{GP}_{5}$ apparently accumulates within the ER compartment as a glycoprotein that possesses high-mannose $\mathrm{N}$-linked oligosaccharide side chains sensitive to endo- $\beta$ - $\mathrm{N}$-acetylglucosaminidase $\mathrm{H}$ treatment, by contrast to its viral counterpart for which N-linked oligosaccharide side chains are of both high-mannose and complex types. Coinfection of 293 cells with hAdVs expressing the $\mathrm{M}$ and $\mathrm{GP}_{5}$

\footnotetext{
*In memoriam. The authors wish to offer their condolences to the family and friends of Dr. Serge Dea, who died on January 3, 2003, and acknowledge his tremendous accomplishment in the field of Nidoviruses.
} 
did not lead to $\mathrm{M}-\mathrm{GP}_{5}$ heterodimer formation, as demonstrated in PRRSV-infected cells. Moreover, cells infected with inducible hAdV/ORF5 showed that $\mathrm{GP}_{5}$ of the North American strain is proapoptotic. Indeed, when the expression cassette was turned-on, caspase 3 activity in hAdV/ORF5 infected cells was enhanced and DNA fragmentation could be detected by TUNEL assays. Pigs intradermally injected twice with hAdV/ORF5 developed antibody titers to the authentic viral $\mathrm{GP}_{5}$ as soon as 10 days following challenge with the homologous virulent PRRSV strain, as revealed by Western blot and virus neutralization tests, suggesting the establishment of a specific immune memory.

\section{Introduction}

Porcine respiratory and reproductive syndrome virus (PRRSV) is the causative agent of an economically important pig disease, with a worlwide distribution, characterized by reproductive failure in sows of any parities and respiratory problems in unweaned and growing pigs $[10,16]$. The virus is morphologically, structurally and genomically similar to other members of the genus Arterivirus, which also includes Equine arteritis virus (EAV), murine Lactate dehydrogenaseelevating virus (LDV) and Simian hemorrhagic fever virus (SHFV) [10, 29, 39]. These viruses, as well as PRRSV, were recently classified in the order Nidovirales, which includes members of the Arteriviridae and Coronaviridae families [4]. The viral genome consists in a positive single-stranded polyadenylated RNA molecule of approximately $15 \mathrm{~kb}$ in length and is composed of nine open reading frames (ORF1a, ORF1b, ORF2a, ORF2b, and ORF3-7) which are expressed as a nested set of sub-genomic mRNAs [29, 30, 39, 46]. Sequence analysis revealed that European and North american strains represent two distinct genotypes, with less than 55\% amino acid (aa) identities for proteins encoded by ORFs 2, 4, and 5 [10]. The ORF1, representing nearly $75 \%$ of the viral genome, encodes for proteins with replicase and polymerase activities [39]. The ORFs 5 to 7 encode for the three major structural proteins of the virion: the envelope glycoprotein $\mathrm{GP}_{5}(25-26 \mathrm{kDa})$, the non-glycosylated membrane protein $\mathrm{M}(18-19 \mathrm{kDa})$ and the nucleocapsid protein $\mathrm{N}(14-15 \mathrm{kDa})[23,24,30]$. These structural proteins are closely associated both in the infected-cells and in the virion, the association of $\mathrm{GP}_{5}$ and $\mathrm{M}$ into disulfide-linked heterodimers being essential for authentic maturation and post-translational modification of $\mathrm{GP}_{5}$ [24], as previously demonstrated for the homologous $\mathrm{G}_{\mathrm{L}}$ and $\mathrm{M}$ envelope proteins of EAV [9].

Circulating antibodies in PRRSV-infected pigs responsible for viral neutralization (VN) in cell cultures are mainly directed against $\mathrm{GP}_{5}$ [15], and neutralizing monoclonal antibodies have been obtained following immunization of Balb/c mice with $E$. coli-expressed GST-ORF5 rec fusion protein [33]. More recently, genetic immunization of pigs with plasmidic DNA encoding the ORF5 gene not only triggered the immune system for the production of anti-PRRSV neutralizing antibodies, but also conferred protection against development of clinical disease and lung lesions following intratracheal challenge with the homologous virulent strain [34]. However, DNA immunization was apparently not sufficient to inhibit 
virus persistence and shedding in the respiratory tract of challenged pigs. On the other hand, when E. coli-expressed GST-ORF5 rec fusion protein was used as immunogen prior to a challenge with pathogenic virus, the disease was more severe despite the development of high titers ( $>2048$ ) of non-neutralizing antibodies to $\mathrm{GP}_{5}$ [34]. Data obtained suggest that the immune response to unglycosylated linear epitopes of E. coli-expressed ORF5 product is not sufficient to protect pigs [34], and that the establishment of an effective mucosal immunity against glycosylated and conformational dependent epitopes is probably crucial, particularly to control virus persistence and shedding. However, this aspect of immunity against PRRSV has not been investigated so far. Consequently, the use of viral vectors with the ability to infect pig cells of the intestinal or respiratory tract, such as adenoviral and poxviral vectors, could be preferable to produce large amounts of recGP $\mathrm{P}_{5}$ that have conserved the major characteristics of the authentic viral glycoprotein [45].

Live human adenovirus type 5 (hAd5) has been shown to be an excellent delivery system for vaccine immunogens [17, 45, 47]. Both replication-defective and replication-competent hAd5 vectors (hAdV) have been used for insertion of foreign genes [17]. However, replication-defective viruses, which have been deleted for the E1 genomic region $(\Delta \mathrm{E} 1)$ that is known to be crucial for virus replication, are often preferred to replication-competent vectors for their biosafety. Indeed, under those conditions, the vaccinated animals are expected to be unable to shed infectious viruses that could dissiminated to unvaccinated pigs kept in the same building. Therefore, there is no risk for human of being infected by a replicative $\mathrm{hAdV}$ either from direct contact, meat or animal by-products. Although unable to replicate in vivo, $\Delta \mathrm{E} 1 \mathrm{hAdVs}$ can induce an immune response to inserted gene products after systemic or intranasal administration [12, 14, 31]. More specifically, the efficacy in swine of $\mathrm{hAdV}$ as recombinant vaccine carrying genes of a variety of swine pathogens was demonstrated [3, 43, 44]. The main objectives of the present study were to construct replication-defective hAdVs expressing the three major structural proteins of PRRSV in a vaccine strategy overview and to compare the adenoviral-expressed recGP 5 protein to the authentic PRRSV protein in terms of cellular processing and final maturation, antigenicity, immunogenicity and proapoptotic activity.

\section{Materials and methods}

Viruses, cells and antisera

The Québec cytopathogenic IAF-Klop strain of PRRSV was propagated in MARC-145 cells, as previously described [23]. Ad/CMVlacZ [1], a replication-defective E1- and E3-deleted hAd5, as well as rec hAdVs, were propagated in 293 cells (ATCC CRL-1573). Infectivity titers of hAdVs stocks were determined by calculation of plaque forming units (PFU) per $\mathrm{ml}$ on 293 cell monolayers [18]. AdCMV/tTA, which permits the constitutive expression of the tetracycline transactivator (tTA) under the control of the constitutive human CMV immediate-early promoter/enhancer was used in co-infection to allow expression of rec proteins in cells infected with hAdVs expressing the transgenes under the control of the TR5 promoter. Doxycycline (Sigma-Aldrich Canada Ltd, Oakville, Ontario, Canada) $(1 \mu \mathrm{g} / \mathrm{ml})$ 
was used to inhibit expression of the transgenes in hAdV-infected cells [26]. The 293 TetOn cells (Clontech Laboratories Inc., Palo Alto, California, U.S.A.), that constitutively express the reverse tetracycline transactivator ( $\mathrm{rtTA}$ ), were cultivated in the presence of $1 \mu \mathrm{g} / \mathrm{ml}$ of doxycycline to induce the expression of the transgenes driven by the tetracycline-regulatable promoter (TR5) [26]. BMAdE1 cells, an A549 cell line expressing AdE1 proteins from a vector designed to eliminate the generation of replication competent adenoviruses [25], were propagated in similar conditions as 293 cells [1]. Hyperimmune rabbit monospecific antisera $\alpha 5, \alpha 6$ and $\alpha 7$, directed respectively against $\mathrm{GP}_{5}, \mathrm{M}$ and $\mathrm{N}$ proteins of the homologous IAF-Klop PRRSV strain expressed in E. coli, were obtained from previous studies [24].

\section{Generation of replication-defective hAdVs expressing PRRSV N, M and $\mathrm{GP}_{5}$ proteins}

The ORF5, 6 and 7 coding sequences of the IAF-Klop strain of PRRSV were amplified by RT-PCR using specific sets of oligonucleotide primers, which were designed from the nt sequence determined in a previous study (EMBL/Genbank accession No. U64928) [15]. All primers contained two Bam HI restriction sites at their $5^{\prime}$ end, and in the case of sense primers, the ATG initiator codon was preceded by a triple GCC motif in order to provide an optimal Kozak consensus sequence for efficient translation [20]. For each reaction, the amplified product was inserted into the unique BamHI site of the pAdCMV5 or pAdTR5 transfer vectors [26], to ensure that the transgenes would be under the control of the constitutive hCMV immediate-early promoter/enhancer (pAdCMV5) or the tetracycline-regulatable promotor (pAdTR5). The rec plasmids were rescued into the genome of Ad/CMVlacZ by homologous recombination in 293 cells, as described elsewhere [18]. Upon cotransfection, virus plaques were isolated, amplified in 293 cells, and analyzed for the expression of the rec proteins (recN, recM and rec-GP 5 ) either by Western blot or by radioimmunoprecipitation assays (RIPA). The hAdVs AdTR5/ORF5, AdCMV5/ORF6 and AdTR5/ORF7, which expressed the recombinant $\mathrm{GP}_{5}, \mathrm{M}$ and $\mathrm{N}$ proteins, respectively, were subjected to three consecutive rounds of plaque purification on BMAdE1 clone 78 cells. Subsequently, selected viral clones were amplified on BMAdE1 clone 220 cells, as described elsewhere [27].

\section{Western blot}

Extracellular PRRSV virions produced in MARC-145 cells were concentrated by ultracentrifugation at 100,000 $\mathrm{g}$ (rotor SW40Ti, Beckman) for $3 \mathrm{~h}$ through a $30 \%(\mathrm{~W} / \mathrm{V})$ sucrose cushion in $50 \mathrm{mM}$ Tris-buffered saline (TBS), $\mathrm{pH}$ 8.0. After denaturation by boiling in the presence of $5 \%(\mathrm{~V} / \mathrm{V}) \beta$-mercaptoethanol, viral proteins were subjected to $12 \%$ SDS-PAGE and electrotransferred onto nitrocellulose membranes $(45 \mu \mathrm{m}$ pore size, Schleicher and Schuëll, Xymotech Biosystems, Mount Royal, Québec, Canada) [22]. Immunological detection of the authentic $\mathrm{GP}_{5}$ protein was performed following incubation of the saturated nitrocellulose membranes in the presence of 1:500 dilution of the rabbit $\alpha 5$ monospecific antiserum (positive control) or 1:50 dilution of pig sera immunized with recombinant adenoviruses, as previously described [23, 24].

\section{Metabolic labelling, immunoprecipitation and endoglycosidases treatment of PRRSV authentic or recombinant proteins}

Radiolabelling with $\left[{ }^{35} \mathrm{~S}\right]$-methionine (specific activity $1,120 \mathrm{Ci} / \mathrm{mmole}$, Amersham Searle Co., Oakville, Ontario) of viral proteins synthesized in PRRSV-infected MARC-145 cells, as well as rec proteins synthesized in 293 or 293 TetOn cells infected with hAdVs, was carried out essentially as described elsewhere [23, 24]. The precipitated immune complexes were adsorbed for $2 \mathrm{~h}$ to protein A-sepharose CL4B beads (Amersham Pharmacia Biotech, Baie 
d'Urfé, Québec, Canada) and dissolved directly in electrophoresis sample buffer containing $5 \% \beta$-mercaptoethanol. Overnight treatments at $37^{\circ} \mathrm{C}$ of eluted immunoprecipitated proteins with 4, 200 and $3 \mathrm{mU}$ of endoglycosidase (endo- $\beta$ - $\mathrm{N}$-acetylglucosaminidase $\mathrm{H}$ or Endo $\mathrm{H}$, endoglycosidase F/N-Glycosidase F or Glyco F, endo- $\beta$-Galactosidase or Endo $\beta$ ) were done, as previously described [24]. Thereafter, immunoprecipitates were analyzed by $12 \%$ SDSPAGE and fluorography [23].

\section{In vitro inhibition of $\mathrm{N}$-linked glycosylation and protein transport}

For N-linked glycosylation and protein transport inhibition experiments, infected 293 cells were pretreated for $1 \mathrm{~h}$ with $5 \mu \mathrm{g} / \mathrm{ml}$ of brefeldin A (BFA; Sigma-Aldrich Canada Ltd, Oakville, Ontario Canada), in methionine-deprived DMEM prior to labelling with $\left[{ }^{35} \mathrm{~S}\right]$ methionine in the presence of the aforementioned drugs. When labelling was carried out overnight in the presence of BFA, the latter was added freshly every $4 \mathrm{~h}$, since BFA is unstable during incubation [24].

\section{Evaluation of the cytotoxicity and proapoptotic activity of recombinant proteins}

Monolayers of MARC-145 cells were infected with PRRSV IAF-Klop strain at a MOI of 0.4 TCID $_{50}$ per cell or coinfected with AdTR5/ORF5 and AdCMV/tTA at a MOI of $100 \mathrm{PFU}$ per cell of both viruses, in the presence or absence of $1 \mu \mathrm{g} / \mathrm{ml}$ of doxycycline. Cellular changes associated with intracellular synthesis of the recGP 5 were visualized at $70 \mathrm{~h}$ pi under a light microscope (Leitz, Leica Microsystems Inc., Richmond Hill, Canada). A commercial TUNEL assay (In situ cell death detection kit, fluorescein, Roche, Laval, Québec, Canada) was used for the detection of DNA fragmentation in PRRSV and hAdVs-infected cells. Apoptosis was also assessed by detecting the activation of procaspase 3 . At $72 \mathrm{~h}$ pi, MARC- 145 cells that have been coinfected with AdTR5/ORF5 and AdCMV/tTA or infected with IAF-Klop virus (MOI: $0.04 \mathrm{TCID}_{50} /$ cell) were disrupted in a lysis solution from the ApoAlert Caspase ${ }^{\circledR}$ Fluorescent Assay Kit (Clontech Laboratories Inc., Palo Alto, California, U.S.A.). Five $\mu 1$ (corresponding to 60 to $75 \mu \mathrm{g}$ of protein) of the cell lysates were added to $90 \mu \mathrm{l}$ of a solution containing $50 \mathrm{mM}$ HEPES, pH 7.0, $10 \%$ glycerol, 0.1\% CHAPS, $2 \mathrm{mM}$ EDTA and $5 \mathrm{mM}$ DTT. Then, $10 \mu \mathrm{M}$ of a specific substrate for caspase 3, the DEVD-AMC fluorogenic substrate (Biomol Research Laboratories Inc., Plymouth Meeting, PA, U.S.A.), was added and the rate of fluorescence released was monitored with a 96-well plate fluorometer (Cytofluor, Perseptive Biosystems, Foster City, CA, U.S.A.). The results were expressed as fluorescence released (fluorescence units or FU) per second per $\mu \mathrm{g}$ of cell lysates.

\section{Pig immunization}

Nine crossbred F1 (Landrace $\times$ Yorkshire) castrated specific pathogen-free (SPF) piglets, four to five weeks of age, were obtained from a breeding farm located in Southern Québec. The breeding stock and piglets were tested and proven to be seronegative for PRRSV, encephalomyocarditis virus (EMCV), porcine parvovirus (PPV), haemagglutinating encephalomyelitis virus (HEV), swine influenza virues H1N1 and H3N2, transmissible gastroenteritis virus (TGEV) and Mycoplasma hyopneumoniae. The piglets used in this study were from two different litters and were randomly divided into one control group of three pigs and one experimental group of six pigs kept in facilities equipped with a microorganism-free, filtered in-flowing and out-flowing air system. The animals were fed commercial feed and water ad libitum. The six experimental pigs were inoculated with $1 \times 10^{9} \mathrm{PFU}$ of the hAdV AdTR5/ORF5 and $5 \times 10^{9} \mathrm{PFU}$ of the hAdV AdCMV/tTA in a mixture containing $100 \mu \mathrm{L}$ of PBS and $100 \mu \mathrm{L}$ of the poloxamer SP1017 0,02\% (Suprateck Pharma Inc., Laval, Qc, 
Canada) [21]. The viral mixture was administered intradermally under the right ear using a 30 gauge needle. The three control pigs received by the same route of immunization a mixture of $100 \mu \mathrm{L}$ of the hAdV AdCMV/tTA in PBS and $100 \mu \mathrm{L}$ of the SP1017 poloxamer. The animals received a booster of the appropriate antigenic mixture at day 32, and were challenged intranasally at day 60 with $10^{5}$ TCID $_{50}$ of the IAF-Klop strain in $5 \mathrm{ml}$ of clarified cell culture supernatant fluid. Pigs were bled at post-challenge days 0,10 and 21 .

\section{Results}

\section{Generation of the $h A d V s$}

Preliminary attempts to generate replication-defective hAdVs expressing in mamalian cells the products of ORFs 5 and 7 genes of the North American IAFKlop strain of PRRSV were unsuccessful. Apparently, high level of intracellular synthesis of the $\mathrm{GP}_{5}$ and $\mathrm{N}$ proteins interfered with replication or assembly of the hAdVs. Indeed, replication-defective hAdVs could be generated by substitution of the constitutive expression cassette of the pAdCMV5 transfer vector by an inducible vector in which the tetracycline-regulatable promoter was used to control the level of transcription of the transgenes in the cells. On the other hand, hAdVs expressing constitutively the recM protein could be obtained, but viral stocks had only infectivity titers of $10^{7} \mathrm{PFU}$ per ml. Usually, infectivity titers of recombinant hAdV viral stocks vary between $10^{8}-10^{10} \mathrm{PFU} / \mathrm{ml}$ and even more following virus purification by isopycnic ultracentrifugation. RIPA experiments, in which lysates of hAdVs-infected 293 cells were incubated with specifc rabbit hyperimmune sera raised to GST-ORF5 $(\alpha 5)$, -ORF6 $(\alpha 6)$ and -ORF7 $(\alpha 7)$ rec fusion proteins of the homologous virus, permitted visualization of immunoprecipitated polypeptides co-migrating with the authentic major viral structural proteins, $\mathrm{GP}_{5}, \mathrm{M}$ and $\mathrm{N}$ (Fig. 1). Data suggested that hAdV-expressed rec proteins conserved most antigenic determinants of the authentic viral structural proteins. The recGP $\mathrm{O}_{5}$ of the IAF-Klop strain was also recognized by heterologous monospecific rabbit hyperimmune serum raised toward GST-ORF5 recombinant fusion proteins generated for five other prototype PRRSV strains, either from North America or Europe, a further evidence that antigenicity of the recGP 5 was most entirely conserved [35]. As previously reported by Mardassi et al. (1996), in RIPA experiments the three major structural proteins synthesized in PRRSV-infected MARC-145 cells coprecipitated (Fig. 1) because of their proteinic interactions, such as the presence of disulfide bonds.

\section{Glycosylated nature of the recGP 5}

The reactivity profiles of the monospecific rabbit $\alpha 6$ and $\alpha 7$ hyperimmune sera, when tested by RIPA with lysates of 293 cells infected with either AdCMV5/ORF6 or AdTR5/ORF7, and deduced $M_{\mathrm{r}} \mathrm{s}$ of the recM and recN proteins, were indistinguishable from those obtained with the authentic viral $\mathrm{M}$ and $\mathrm{N}$ proteins. However, reactivity profiles obtained with monospecific rabbit $\alpha 5$ hyperimmune serum, when tested with lysates of PRRSV-infected MARC-145 and 293 cells, 


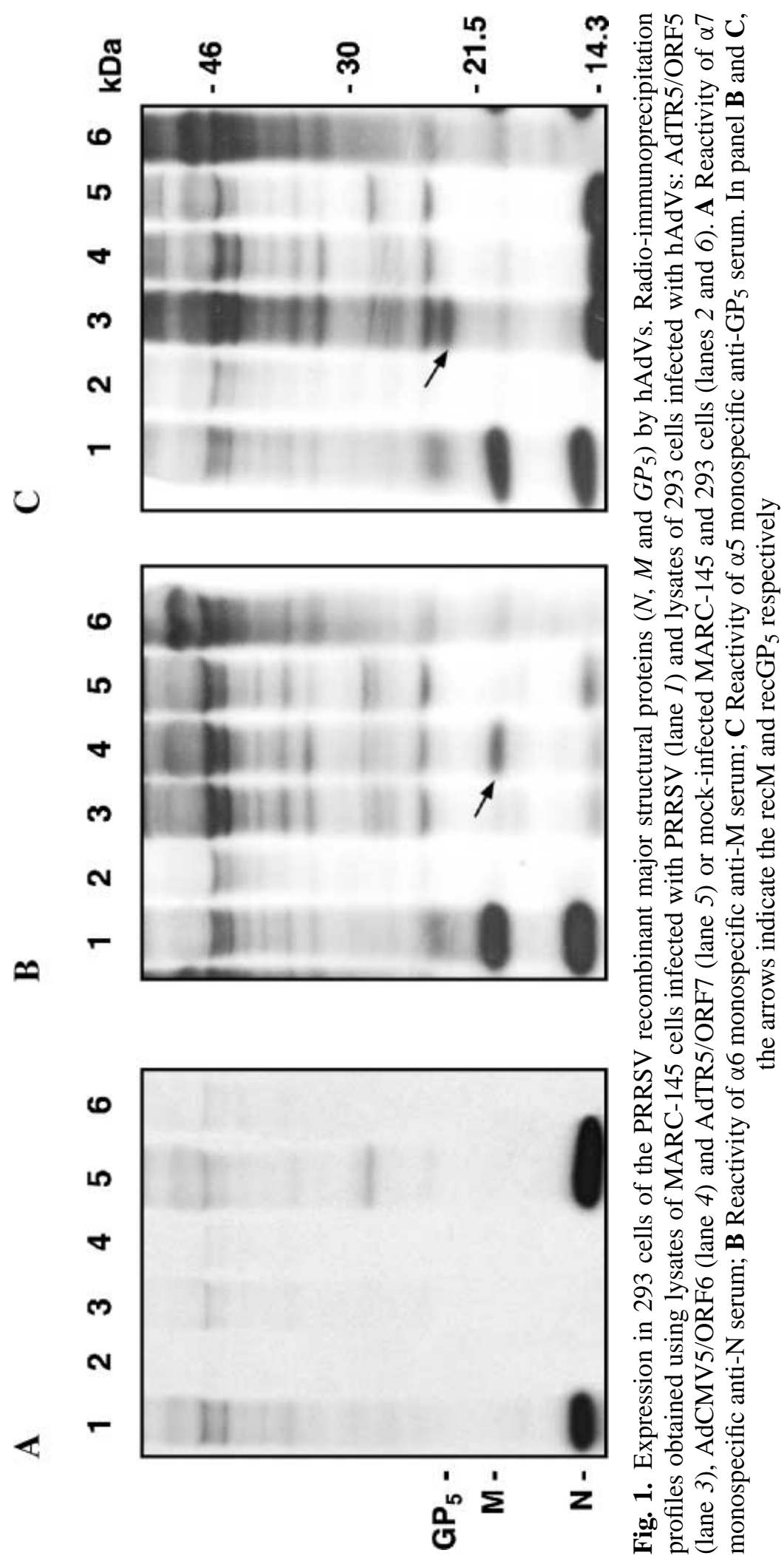




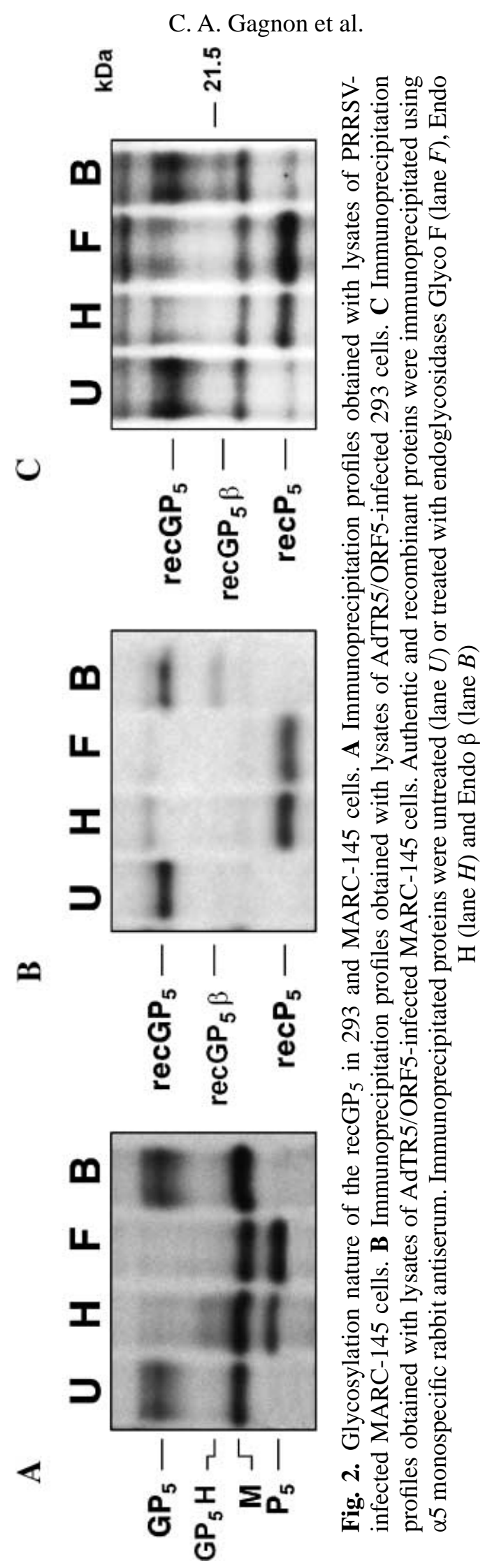


or infected with AdTR5/ORF5 after treatment with various endoglycosidases, suggested that the oligosaccharide residues of the recGP $\mathrm{P}_{5}$ differ from those of the authentic major envelope $\mathrm{GP}_{5}$ glycoprotein. Consistent with previous findings [24], the monospecific $\alpha 5$ antiserum coprecipitated the M protein being associated with the $\mathrm{GP}_{5}$ as disulfide-linked heterodimers in PRRSV-infected cells (Fig. 2a). Also, the authentic GP $_{5}$ synthesized in PRRSV-infected MARC-145 cells appeared as a highly glycosylated protein with estimated $M_{\mathrm{r}}$ of $25 \mathrm{kDa}$ that was converted to a single species of $16,5 \mathrm{kDa}\left(\mathrm{P}_{5}\right)$ following treatment with Glyco F, an endoglycosidase known to cleave all N-linked oligosaccharides side chains [24]. However, it was totally resistant to Endo $\beta$ (Fig. 2a), indicating that it lacks $N$-linked glycans modified by poly- $N$-acetyllactosamine [24]. On the other hand, treatment with Endo H (Fig. 2a), which cleaves high-mannose and hybrid oligosaccharides [24], demonstrated that the authentic viral $\mathrm{GP}_{5}$ is partially sensitive to this glycosidase giving rise to at least two protein species of $16,5 \mathrm{kDa}\left(\mathrm{P}_{5}\right)$ and $21-22 \mathrm{kDa}$ (named $\mathrm{GP}_{5} \mathrm{H}$ for sensitivity to Endo $\mathrm{H}$ ), suggestive

A

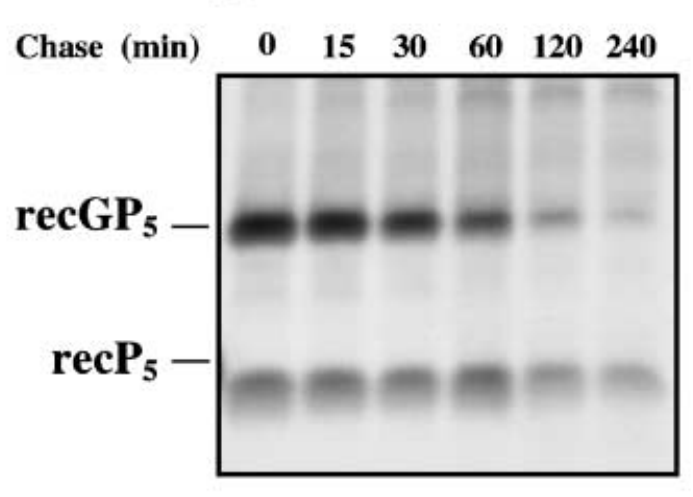

C

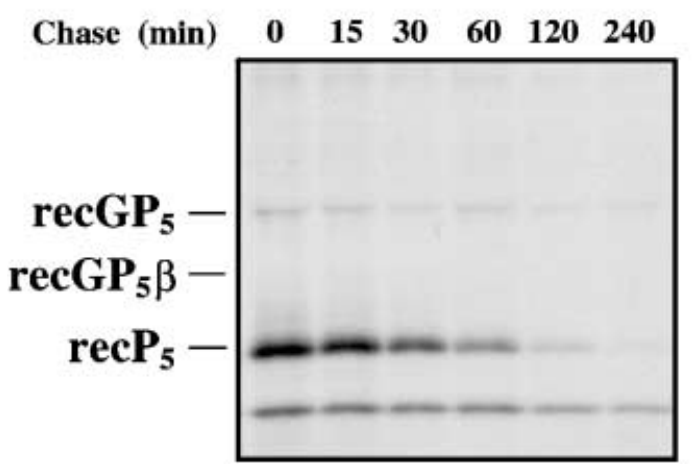

B

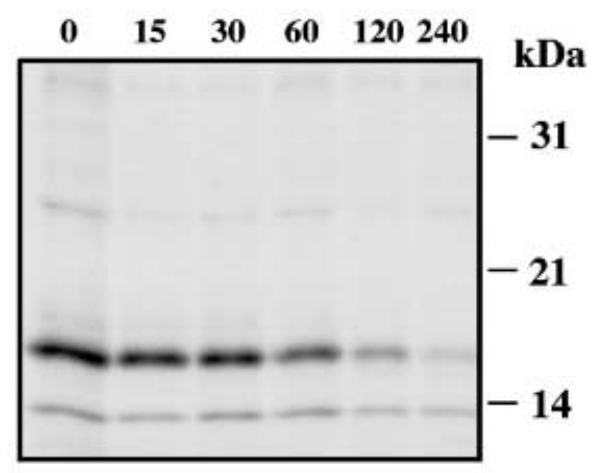

D

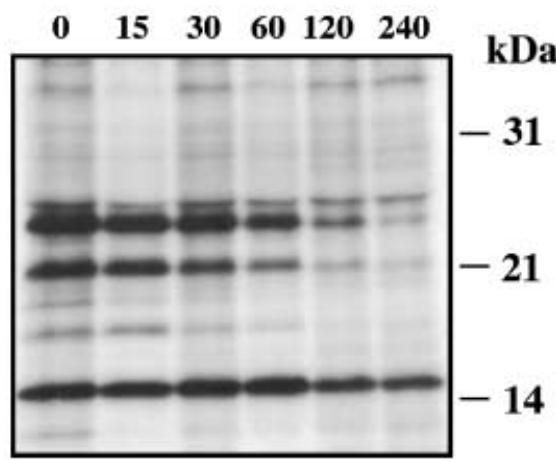

Fig. 3. Processing of the recGP 5 in AdTR5/ORF5-infected 293 cells. AdTR5/ORF5-infected 293 cells were pulse-labelled with $\left[{ }^{35} \mathrm{~S}\right]$ methionine for $30 \mathrm{~min}$, then washed and chased with DMEM containing $5 \mathrm{mM}$ of cold L-methionine. RIPA were performed with cell lysates prepared after the indicated chase period and the immunoprecipitated proteins were untreated

(A) or treated with endoglycosidases; Glyco F (B), Endo H (C) and Endo $\beta$ (D) 
of the presence of $\mathrm{N}$-linked oligosaccharides of the complex type. Consequently, data indicated that recGP 5 lacks $\mathrm{N}$-linked oligosaccharides of the complex type since it was totally sensitive to Endo $\mathrm{H}$ (Fig. 2b). The recGP 5 was rather partially sensitive to digestion with Endo $\beta$, giving rise to two protein species of $20-22 \mathrm{kDa}$ (named recGP 5 for sensitivity to Endo $\beta$ ) and $25 \mathrm{kDa}\left(\mathrm{recGP}_{5}\right.$ ), respectively. In order to certify that differences in the glycosylation nature of recGP $\mathrm{G}_{5}$ were independent of the cell type used to propagate the hAVds, MARC-145 cells were coinfected with AdCMV5/tTA and AdTR5/ORF5. Upon individual expression in these cells, the recGP ${ }_{5}$ appeared to be similarly glycosylated than after propagation of the hAdVs in 293 cells (Fig. 2c).

\section{Processing of recGP $P_{5}$ individually expressed in 293 cells}

Pulse-chase experiments were performed to examine in greater detail the fate of recGP 5 upon expression in 293 cells (Fig. 3). Sensitivity to Endo H and partial resistance to Endo $\beta$ glycosidases were maintained during the $240 \mathrm{~min}$ chase period (Fig. 3c,d), suggesting that individually expressed recGP $\mathrm{G}_{5}$ in 293 cells probably accumulated in the ER, being subjected to partial modification by poly-N-acetyllactosamine. In further experiments, the transport of $\mathrm{GP}_{5}$ in PRRSV-infected MARC-145 cells was shown to be blocked by the addition of BFA in the culture medium (Fig. 4), a chemical which inhibits translocation of proteins from the ER to the Golgi compartment [19]. In the presence of this inhibitor, $\mathrm{GP}_{5}$ synthesized in the context of a PRRSV-infection did not acquire any Endo $\mathrm{H}$ resistance (Fig. 4). The results obtained indicate that during the maturation cycle of PRRSV, GP $\mathrm{F}_{5}$ first accumulated in the ER in the form of $\mathrm{P}_{5}$,
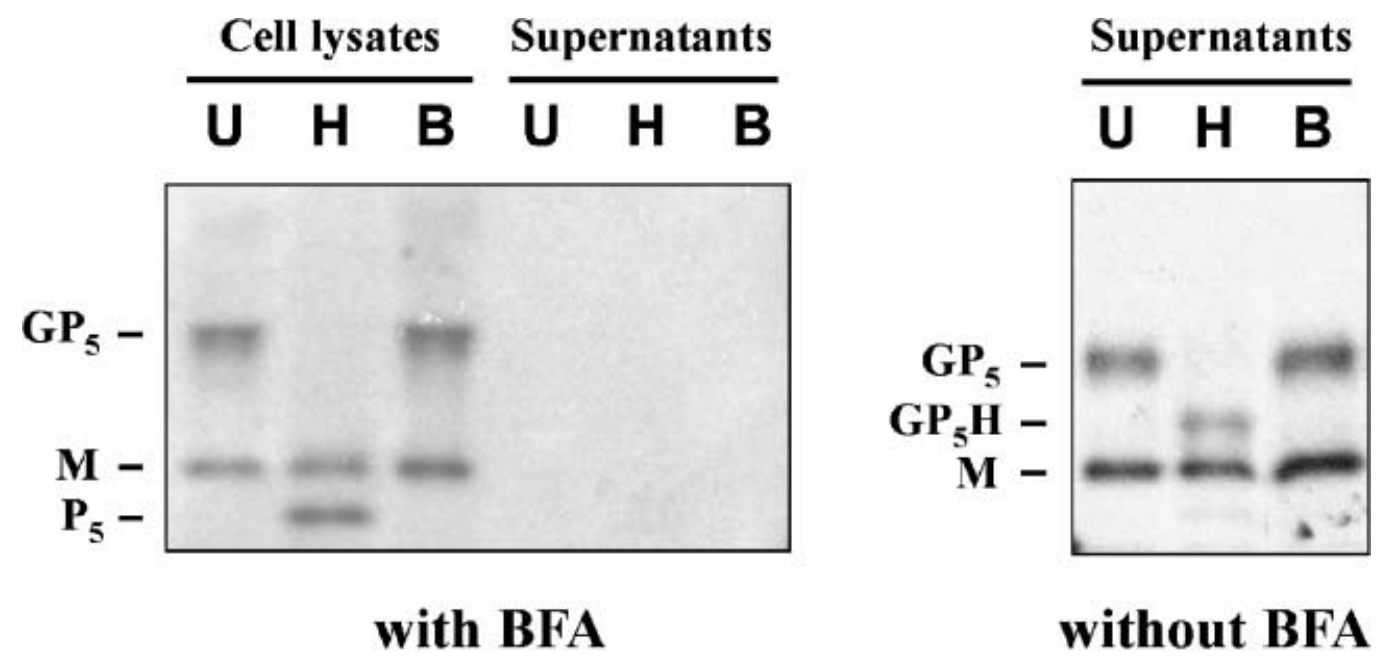

Fig. 4. Transport inhibition of the $\mathrm{GP}_{5}$ major envelope-associated glycoprotein. PRRSVinfected MARC-145 cells were incubated with or without $5 \mu \mathrm{g} / \mathrm{ml}$ of BFA and RIPA were done on cell lysates and supernatant of infected cells using the monospecific $\alpha 5$ antiserum. Immunoprecipitated proteins were untreated $(U)$ or treated with endoglycosidases: Endo $\mathrm{H}$ (lane $H$ ) and Endo $\beta$ (lane $B$ ) 
as demonstrated with the individually expressed recGP $_{5}$ (Fig. 2b). Neither the three major viral structural proteins (Fig. 4), nor assembled viral particles (data not shown), could be found in the supernatant fluids of PRRSV-infected cells in the presence of BFA, contrarily to the situation observed in the absence of BFA (Fig. 4). Therefore, through its transport from the ER to the Golgi apparatus, the $\mathrm{GP}_{5}$ apparently acquires oligosaccharide side chains of the complex type, giving rise to a $21-22 \mathrm{kDa}$ protein species $\left(\mathrm{GP}_{5} \mathrm{H}\right)$ (Fig. 4). As previously described [24], $\mathrm{GP}_{5} \mathrm{H}$ was the protein species incorporated in the mature virions. Contrarily to the modifications of recGP $\mathrm{GP}_{5}$ observed in cells that have been infected with AdTR5/ORF5, the authentic GP $_{5}$ synthesized following PRRSV infection remained resistant to Endo $\beta$ glycosidase even if its transport was blocked in the ER (Fig. 2b and 4). As a constituent of the envelope of mature virions, $\mathrm{GP}_{5}$ has been previously found to be associated with $\mathrm{M}$ in the form of disulfide-linked heterodimers [24]. However, coinfection of 293 cells with hAdVs expressing individually the recN, recM or recGP $\mathrm{GP}_{5}$ protein did not change the fate of the recGP (Fig. 5). Although the simultaneous expression of the recM and recGP $\mathrm{G}_{5}$ could be detected in the infected 293 cells (Fig. 5), no heterodimer recM-recGP ${ }_{5}$ formation could be demonstrated (data not shown). Furthermore, no coprecipitation of the recGP $_{5}$ and recM was demonstrated following incubation of the monospecific rabbit $\alpha 6$ hyperimmune serum with hAdV/ORF5 and hAdV/ORF6-coinfected cell lysates (data not shown), contrarily to the situation observed with lysates of

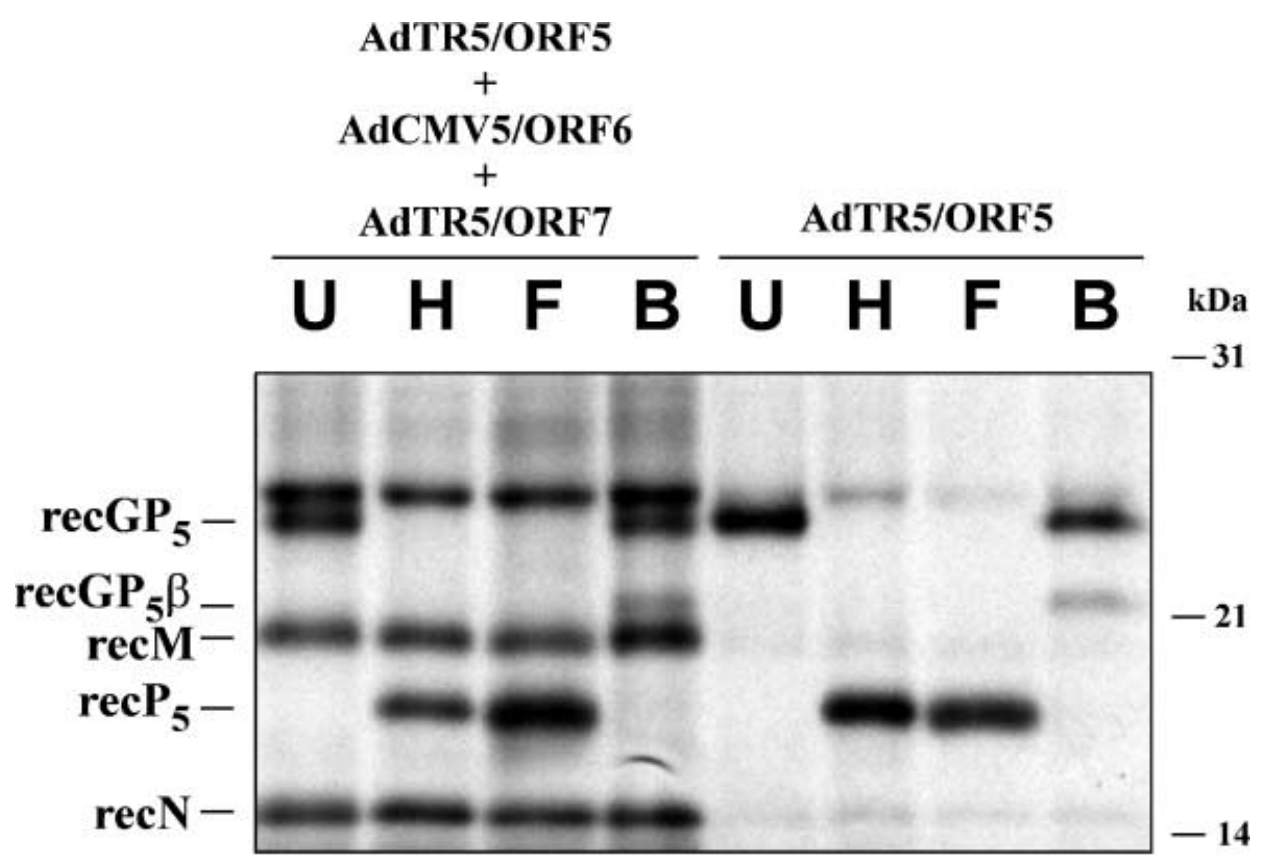

Fig. 5. Glycosylation nature of the coexpressed recN, recM and recGP 5 proteins in 293 cells. Radiolabelled recombinant proteins were immunoprecipitated with $\alpha 5$, $\alpha 6$ and $\alpha 7$ antisera and untreated (lane $U$ ) or treated with endoglycosidases; Glyco F (lane $F$ ), Endo H (lane $H$ ) and Endo $\beta$ (lane $B$ ) 
A

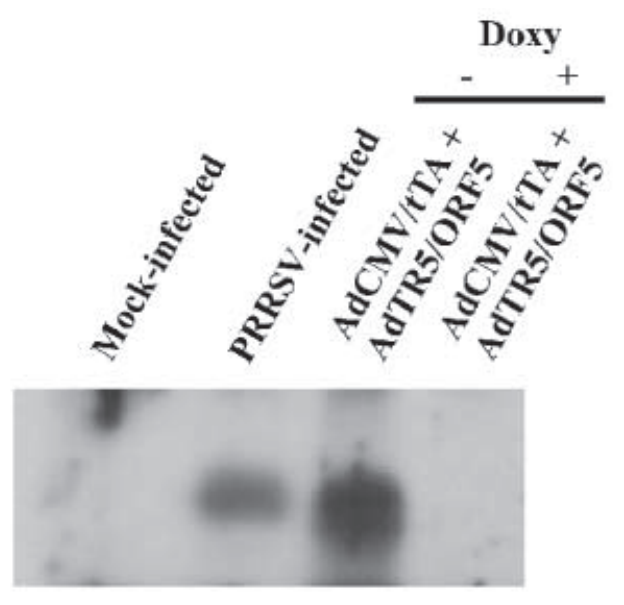

B

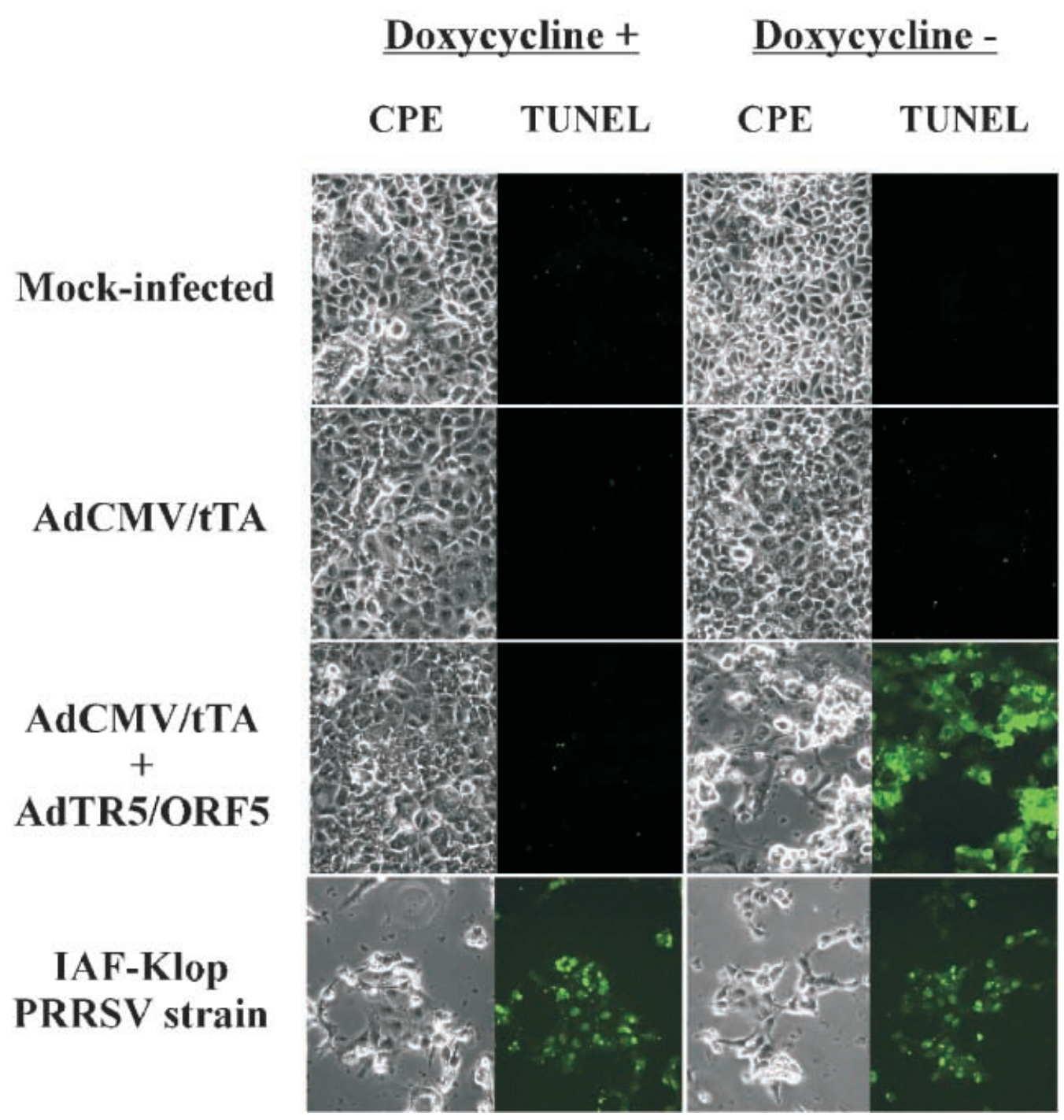


PRRSV-infected cell cultures wherein the formation of $\mathrm{GP}_{5}-\mathrm{M}$ heterodimers was previously found to occur [24].

\section{Proapoptotic activity of $h A d V$-expressed recGP 5 protein in MARC-145 cells}

Coinfection of MARC-145 cells with AdCMV/tTA and AdTR5/ORF5 permitted the expression of recGP 5 which was completely inhibited in the presence of doxycycline (Fig. 6a). Interestingly, when recGP 5 was expressed individually in MARC-145 cells, cellular degenerescence was observed (Fig. 6b). These degenerative changes were neither observed when doxycycline was added to the medium (Fig. 6b, left panel) nor in cells expressing the recN protein alone (data not shown). The cellular changes observed with recGP $\mathrm{G}_{5}$ appeared almost identical to those observed in the PRRSV-infected cell cultures [23]. Indeed, scattered and enlarged cells with very small granular inclusions in their cytoplasm usually started to be detectable by $24 \mathrm{~h}$ pi, then infected cells showed a tendency to clump into foci that could be well delineated from the unaffected monolayer by 36 to $48 \mathrm{~h}$ pi. Many of the infected cells eventually detached from the surface of the culture flask, more than $75 \%$ of the cell monolayer being severely damaged by $72 \mathrm{~h}$ pi. To test whether the observed cytotoxicity was due to apoptosis, cells were assayed for the presence of DNA fragmentation by a TUNEL fluorescent assay, 3 days after infection. As illustrated in Fig. 6b, positive fluorescent cells were detected only when $\mathrm{GP}_{5}$ expression was turned on and only in areas affected by degenerative damages. DNA fragmentation was also detected in PRRSV-infected cells (Fig. 6b). Additional evidence that apoptosis was occurring in AdTR5/ORF5infected cells was obtained by the demonstration of procaspase 3 activation. As depicted in Fig. 7, an important increase in caspase 3 activity was detected only in cells expressing the recGP $\mathrm{G}_{5}$. Addition of doxycycline to inhibit recGP $\mathrm{GP}_{5}$ expression did repress the procaspase 3 activation which was detected at the same level than in control cell cultures which had been infected with AdCMV/tTA alone. The levels of caspase 3 specifically induced by recGP ${ }_{5}$, that were evaluated from three separate experiments, were at least 39 and 10 fold higher than those detected in the control uninfected cell monolayers and AdCMV/tTA infected cells, respectively. By comparison, PRRSV infection also resulted in procaspase 3 activation, but to a lower extent than AdTR5/ORF5 infection where recGP 5 was individually

Fig. 6. Induction of apoptosis in MARC-145 cells by regulatable expression of the recGP $\mathrm{P}_{5}$ protein. A Detection of the recGP 5 by Western blot in lysates of MARC-145 cells infected with PRRSV IAF-Klop strain or with both AdCMV/tTA and AdTR5/ORF5 in presence or absence of doxycycline using the anti-GP $\mathrm{GP}_{5}$ rabbit monospecific antisera $(\alpha 5)$. B Visualization with a light microscope of the cytopathic effect $(C P E)$ of MARC-145 cells infected with PRRSV IAF-Klop strain and with AdCMV/tTA alone or in combination with AdTR5/ORF5, in presence or absence of doxycycline at $70 \mathrm{~h}$ pi. Visualization of the same hAdV infectedcells with a fluorescence microscope after treatment with a fluorescein TUNEL assay for the detection of DNA fragmentation 


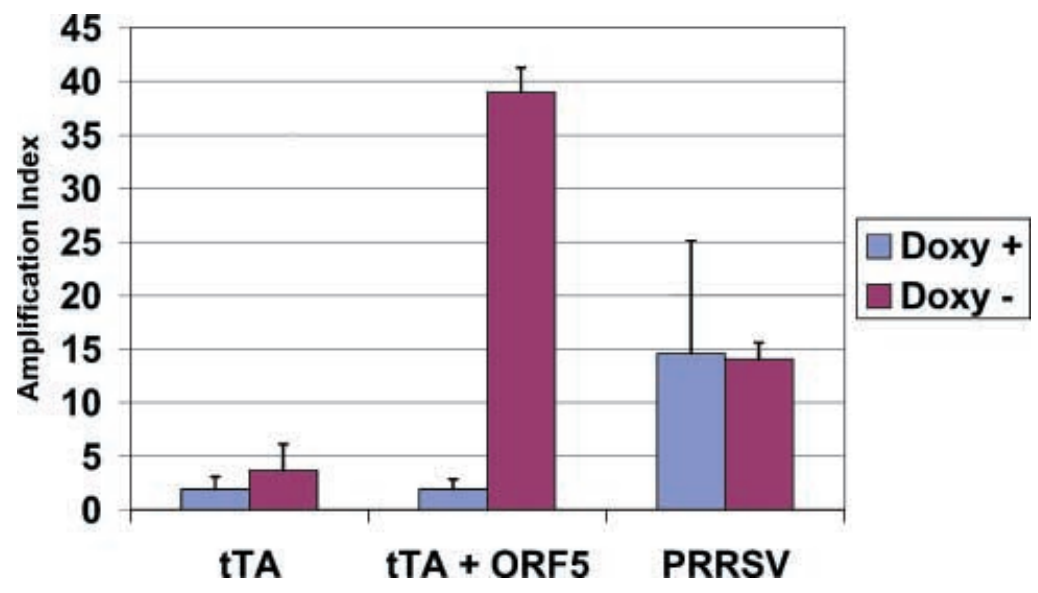

Fig. 7. Procaspase 3 activation. Confluent monolayers of MARC-145 cells were infected with either AdCMV/tTA ( $t T A)$ alone or with both AdCMV/tTA and AdTR5/ORF5 (ORF5) at a MOI of $50 \mathrm{PFU} / \mathrm{cell}$, in the presence or absence of doxycycline. Control MARC-145 cells were mock-infected or infected with IAF-Klop PRRSV strain. Measurement of the procaspase 3 activation was done by quantifying the release of fluorescence and the results were expressed as $\mathrm{FU} /(\mathrm{sec} \times \mu \mathrm{g})$. The amplification indexes represent the level of procaspase 3 activation in infected cells divided by the level of procaspase 3 activation in uninfected cells

A

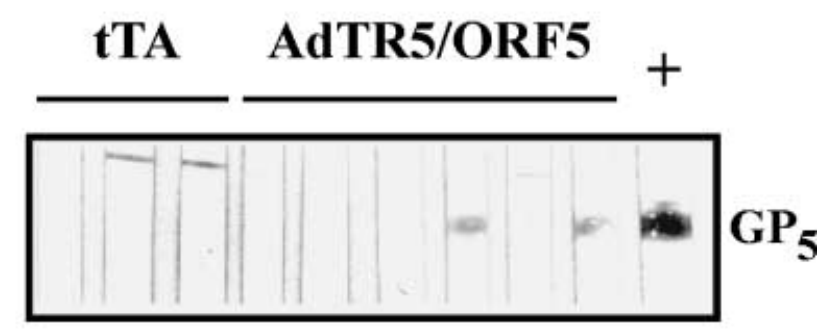

B

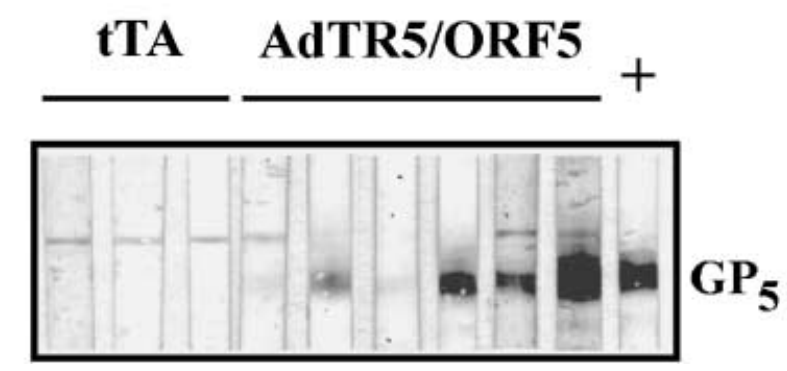

Fig. 8. Serological reactivities of AdTR5/ORF5-immunized pigs toward the authentic viral $\mathrm{GP}_{5}$ protein. Lysates of IAF-Klop PRRSV-infected MARC-145 cells were prepared in RIPA buffer, clarified and electrophoresed on $12 \%$ SDS-polyacrylamide gels. Proteins were electrotransferred onto a nitrocellulose membrane and individual strips were incubated in the presence of serum from the pigs (diluted 1/50) that have been injected twice with AdTR5/ORF5 + AdCMV/tTA (immunized pigs) or AdCMV/tTA (control pigs) alone, and collected at day 10 (A) and day 21 (B) after intranasal challenge with virulent homologous PRRSV strain. tTA: sera of control pigs; AdTR5/ORF5: sera of pigs pre-immunized with AdCMV/tTA plus AdTR5/ORF5; +: reactivity of anti-GP 5 rabbit monospecific antisera $(\alpha 5)$ 
expressed. This was probably due to the lower number of cells expressing the $\mathrm{GP}_{5}$ protein, since an MOI of only 0,04 TCID 50 per cell could be used for PRRSV, as compared to $50 \mathrm{PFU}$ per cell for the hAdV AdTR5/ORF5.

\section{Immune response induced in pigs by hAdV AdTR5/ORF5}

Following two intradermal injections of the mixture AdCMV/tTA and AdTR5/ ORF5, none of the immunized piglets developed significant antibody titers ( $>16)$, as demonstrated either by indirect immunofluorescence (IIF) on PRRSV-infected MARC-145 cells or virus neutralization (VN) [22, 32]. Furthermore, none of the hyperimmunized pigs reacted positively to the authentic $\mathrm{GP}_{5}$ viral protein by Western blot. However, following a challenge with a low dose of virulent virus given intranasally 14 days after the booster, the six AdTR5/ORF5-immunized pigs produced high antibody titers to the authentic viral $\mathrm{GP}_{5}$ protein, a clear signal being obtained by Western blot as soon as 10 days post-challenge (Fig. 8). In comparison, pigs that were vaccinated with the AdCMV/tTA vector alone were still negative by Western blot at day 10 and day 21 post-challenge. Only the pigs that were vaccinated with the AdTR5/ORF5 developed VN antibody titers. Indeed, at day 10 post-challenge, two of the pre-immunized pigs had $\mathrm{VN}$ antibody titers of 128-256, and one had a VN antibody titer of 16 . The control pigs were still negative by $\mathrm{VN}$ at day 21 post-challenge.

\section{Discussion}

In the present study, generation of replication-defective hAdVs expressing constitutively ORFs 5 and 7 of a North American strain of PRRSV under the control of the hCMV immediate-early promoter/enhancer was unsuccessful, despite that such hAdV was obtained for the ORF6. However, infectivity titers of the replicationdefective hAdV/ORF6 propagated in 293 cells, complementing the E1 functions of the hAd5, were at least 10 to 100 fold lower than those usually expected for such recombinant adenoviruses [18]. Further characterization of the authentic $\mathrm{GP}_{5}$ of IAF-Klop strain of PRRSV demonstrates that, as the homologous protein of European strains [40], it induces cell death by apoptosis (Fig. 6b and 7) and appears to be toxic for 293 cells. Both characteristics could explain the failure to generate hAdVs that constitutively express this major envelope glycoprotein of PRRSV. Whether similar phenomena can also interfere with generation of hAdVs that constitutively express the $\mathrm{N}$ protein should be further investigated, as no cytotoxicity in 293 cells transfected with pAdCMV5/ORF7 could be observed (data not shown). However, previous investigators [36] identified the nucleolus of PRRSV-infected cells as the primary site for $\mathrm{N}$ protein localization within the nucleus and have observed some toxicity. Even if cell death did not appear to correlate with this early localization of the N protein during PRRSV replication cycle, it may interfere with some cellular functions required for the generation of hAdVs. Consequently, to generate hAdVs that could express the $\mathrm{GP}_{5}$ and $\mathrm{N}$ proteins, an inducible system was required to be able to control the synthesis 
of both proteins to a threshold level above which they become toxic for the cells and interfere with replication and assembly of hAdVs. This was done by using the tetracycline-regulated promoter contained in the pAdTR 5 transfer vector which has been already reported to permit the construction of hAdVs expressing toxic proteins [26, 27]. In MARC-145 cells, coinfection of hAdVs expressing the tTA transactivator (AdCMV/tTA) with hAdVs expressing the PRRSV structural genes under the control of the tetracycline-regulated promoter (AdTR5/ORF5 and AdTR5/ORF7) was essential to allow efficient expression of PRRSV rec proteins. Addition of doxycycline in the culture medium also completely suppressed expression of the transgenes (Fig. 6a), thus confirming that the tetracycline-regulated expression system was very efficient for controlling the expression levels of both viral proteins, to allow generation of hAdVs carrying the ORFs 5 and 7.

The antigenicity of the recN, recM and recGP 5 expressed by hAdVs (AdTR5/ ORF7, AdCMV5/ORF6 and AdTR5/ORF5) was conserved since the rec proteins could be detected by the homologous monospecific rabbit antiserum raised against the corresponding viral protein expressed in E. coli. [24], by the homologous porcine anti-PRRSV hyperimmune serum, as well as heterologous monospecific rabbit hyperimmune sera raised toward GST-ORF5 recombinant fusion proteins of five other prototype PRRSV strains, either from North America or Europe [35]. Data also suggested that both, linear and conformational epitopes of PRRSV major structural proteins were conserved following expession by the rec hAdVs, despite that glycosylation of the recGP 5 protein was found to be different from that of the authentic $\mathrm{GP}_{5}$. Indeed, whereas the authentic viral $\mathrm{GP}_{5}$ of the IAF-Klop strain was resistant to treatment with Endo $\beta$ glycosidase [24], the individually expressed recGP ${ }_{5}$ was partially sensitive to digestion by this endoglycosidase (Fig. 2). Consequently, by contrast to the authentic viral $\mathrm{GP}_{5}$, the recGP $\mathrm{G}_{5}$ expressed individually by hAdVs possesses $\mathrm{N}$-acetyllactosamine side chain oligosaccharides. Several structural features on the authentic protein (fucose, branching, galactose sulfate residues) may be responsible for its resistance to Endo $\beta$ glycosidase [37]. The presence of such oligosaccharide residues ( $\mathrm{N}$-acetyllactosamine side chains) have been previously reported in the case of the $\mathrm{G}_{\mathrm{L}}$ protein of EAV, the counterpart of the $\mathrm{GP}_{5}$ of PRRSV [8]. The sensitivity of the recGP 5 protein to Endo $\mathrm{H}$ glycosidase is an indication that the individually expressed protein is associated with intracellular membranes or accumulates within the ER. This correlates with the fact that in PRRSV-infected MARC-145 cells incubated with BFA, which inhibits translocation of the proteins to the Golgi apparatus [19], the authentic $\mathrm{GP}_{5}$ remained sensitive to Endo $\mathrm{H}$, as in case of the recGP 5 (Fig. 4). However, even after treatment with BFA, the authentic $\mathrm{GP}_{5}$ still differs from the recGP in regards to their distinct reactivity to Endo $\beta$ digestion. Further studies are required to identify whether this difference can be attributed to interactions with proteins synthesized during the replication of hAdVs or if interactions with other unidentified PRRSV proteins are required for final maturation of $\mathrm{GP}_{5}$ occuring in the Golgi apparatus. The glycosylation state of the $\mathrm{GP}_{5}$ may have an important role to play in its biological activity, as previously demonstrated for LDV in mice for which the glycosylation state of the major envelope structural protein is 
implicated in the neuropathogenicity of the various strains, as well as inactivation by neutralizing antibodies [5].

As for the autologous proteins of EAV, the $\mathrm{GP}_{5}$ and $\mathrm{M}$ proteins of PRRSV form heterodimers prior to the final processing of the N-oligosaccharide side chains of $\mathrm{GP}_{5}[9,24]$. Consequently, the formation of these heterodimers play a key role in the maturation and infectivity of the PRRSV virions [9, 13, 24]. However, in the present study, such heterodimers could not be demonstrated by co-infection experiments with hAdVs-expressed recGP $_{5}$, recM and/or recN proteins (Fig. 5), done in two different cell lines (data not shown). Also, no virionlike particles could be observed in the supernatant medium by negatively stained electron microscopy. Since such heterodimers could not be obtained after transient expression assays of the $\mathrm{M}$ and $\mathrm{GP}_{5}$ proteins in 293 cells co-transfected with the corresponding recombinant transfer vectors (data not shown), it seems unlikely that the hAdVs interfered with the heterodimers formation. It is plausible that other PRRSV proteins are essential for the appropriate folding and glycosylation of the $\mathrm{GP}_{5}$.

Recently, expression of the two major envelope proteins of EAV as heterodimers has been reported to be necessary for induction of neutralizing antibodies in mice immunized with recombinant Venezuelan equine encephalitis (VEE) virus replicon particles [2]. Data obtained in this study can not be generalized for arteriviruses infecting other animal species. Indeed, in previous studies, the production of VN antibodies could also be recovered in pigs, but not in mice, following genetic immunization with plasmidic DNA carrying the PRRSV ORF5 in the absence of $M$ protein [34]. In contrast, VN antibodies to PRRSV could be recovered from the serum of mice following their immunization with E. coli.expressed ORF5 protein [33]. Similarly, in the case of EAV, the presence of VN antibodies could be demonstrated in the sera from horses and mice immunized with synthetic peptides deduced from the aa sequence of the $G_{L}$ protein, or with a bacterial fusion protein [6]. Consequently, the ability of the individually-expressed PRRSV GP 5 protein to induce neutralizing antibodies in pigs was not surprising. The fact that neutralizing antibodies were induced only in mice immunized with the $\mathrm{G}_{\mathrm{L}} / \mathrm{M}$ heterodimers of EAV expressed by recombinant VEE indicates that in the context of the recombinant viral infection, the presence of the $\mathrm{M}$ protein is critical to the expression of neutralizing epitopes, which are apparently conformationdependent. In the case of the PRRSV recombinant $\mathrm{GP}_{5}$ protein individually expressed by hAdVs, data obtained indicate that at least some of the epitopes involved in $\mathrm{VN}$ are available to the antigen presenting cells, and probably that other neutralizing conformation-dependent epitopes may require the interaction with the $\mathrm{M}$ protein to become available to cells involved in the immune response.

In the present study, it has been further demonstrated that immunization (vaccination) of pigs with adenovirus that are able to express the $\mathrm{GP}_{5}$ of PRRSV in the absence of $\mathrm{M}$ protein triggers their immune system for the production of VN antibodies, which however could only be detected 10 days after they have been challenged with a low dose of the virulent homologous virus. These serological data differ significantly from those obtained following natural infection with 
PRRSV, since infected pigs usually do not produce VN until 3 to 4 weeks postinfection $[22,32]$. However, two weeks after the first injection of the rec hAdVs, pigs had developed high specific indirect immunofluorescence (IIF) antibody titers ( $>160)$ to adenovirus structural proteins (data not shown), which may have interfere with an efficient expression of the recGP ${ }_{5}$ and subsequently delayed the establishment of a specific immune response against the $\mathrm{GP}_{5}$. To demonstrate the effectiveness of PRRSV challenge, collected sera were tested for the presence of anti-PRRSV antibodies by IIF, by using a commercial ELISA (IDEXX) and by using an anti-N blocking ELISA [11]. At the day of challenge, all tested sera were negative for antibodies to PRRSV, whereas at 10 days post-challenge, all sera tested positive using those three diagnostic tests, thus confirming the seroconversion to PRRSV (data not shown). Since the latter serological tests were reported to permit detection of antibodies directed only (blocking ELISA) or mainly (IIF and IDEXX ELISA) to the N protein of PRRSV [11], they were expected to be negative or only weakly positive before challenge, since the vaccination was against the $\mathrm{GP}_{5}$ only. In spite of the demonstration that authentic $\mathrm{GP}_{5}$ specific antibodies in experimentally infected pigs sera are only detected no earlier than 28 days post-infection by western blot [22], $\mathrm{GP}_{5}$ specific antibodies could be detected as early as 10 days post-challenge in AdTR5/ORF5 vaccinated pigs. Data obtained suggest that vaccination of pigs with adenovirus expressing recGP $\mathrm{G}_{5}$ at least presensibilized cells from the lymphoid organs and established an immune memory, which following a subsequent PRRSV infection, results in a rapid clonal expansion of memory cells to the neutralizing epitopes of the authentic viral $\mathrm{GP}_{5}$ protein. Since AdCMV/tTA, which permits the constitutive expression of the tetracycline transactivator (tTA), had to be co-inoculated to the pigs with AdTR5/ORF5 to obtain expression of recGP 5 , the in vivo expression of the $\mathrm{GP}_{5}$ may have been less efficient than in cell cultures. Indeed, the cells had to be infected by both rec $\mathrm{hAdVs}$ to express the recGP 5 . Therefore, the vaccinated animals probably did not produce enough antibodies to reach the threshold required to be detected by the serological tests used in the present study. With the type of inducible vector used in this study to control the expression level of recGP 5 , the hAdV strategy was less successful than previously described DNA vaccine [34], since in vivo co-infection of the same cells by AdCMV/tTA and AdTR5/ORF5 could not be controlled. This may explain why only a specific memory immune response was established in vaccinated pigs (Fig. 8).

Recently, an adenovirus expressing both the gene of interest and the tTA has been constructed and proven to be efficient for in vivo expression of the transgene [7]. Other promoters can also be used to repress the expression of a toxic transgene in cells constitutively expressing a repressor protein (like the lac repressor protein). Such promoters allow the generation of hAdVs carrying foreign genes encoding toxic proteins and are efficient to permit high expression of a transgene in other cell lines [28]. In the context of vaccine development using recombinant adenoviruses, those strategies and other alternatives are being studied.

European, as well as North American, strains of PRRSV were reported to induce apoptosis in the infected cells both in vitro and in vivo [40-42]. The 
use of recombinant vaccinia virus expressing the $\mathrm{GP}_{5}$ of the European genotype demonstrated that the major envelope glycoprotein is involved in this pathological phenomenon [40]. In the present study, the proapoptotic phenotype of the IAFKlop $\mathrm{GP}_{5}$ was demonstrated in cells infected with the replication-defective hAdVs using two different approaches: firstly, the demonstration of DNA fragmentation by TUNEL assays (Fig. 6), and secondly, the demonstration of procaspase 3 activation (Fig. 7). Despite only 53\% aa identity between the $\mathrm{GP}_{5}$ of North American and European strains [35], both $\mathrm{GP}_{5}$ display proapoptotic activity. Further studies should permit to identify the $\mathrm{GP}_{5}$ region or aa residues involved and conserved amongst strains from both genotypes. Recently, it has been demonstrated, in vivo and in vitro, that apoptosis occured in PRRSV-uninfected bystander cells [38]. This phenomenon could not be demonstrated in the present study since a MOI of $50 \mathrm{PFU}$ was necessary to obtain sufficient expression of the recGP 5 by the replicationdefective adenovirus vectors. Studies are in progress to further characterize the proapoptotic activity of the $\mathrm{GP}_{5}$ of the IAF-Klop strain and determine which caspase(s) cascade(s) is activated. Previous studies with the Spanish OLOT strain of PRRSV demonstrated that the $\mathrm{GP}_{5}$-induced apoptotic activity could not be prevented by using a cell line permanently expressing the anti-apoptotic bcl-2 gene, suggesting the use of an alternative and/or unknown apoptotic pathway [40].

\section{Acknowledgements}

The authors wish to thank Louise Wilson, Marcel Desrosiers, and François Bouthillier for their excellent technical assistance. This report was taken in part from a dissertation to be submitted by C.A. Gagnon to the INRS-Institut Armand-Frappier, in partial fulfillment of the requirements for the $\mathrm{PhD}$ degree. This work was supported by the Natural Sciences and Engineering Research Council of Canada (Strategic grant STP02002083) and Biovet Inc., StHyacinthe, Quebec, Canada. C.A. Gagnon was a recipient of a fellowship from the Medical Research Council of Canada. This is a NRC publication 46145.

\section{References}

1. Acsadi G, Jani A, Massie B, Simoneau M, Holland P, Blaschuk K, Karpati G (1994) A differential efficiency of adenovirus-mediated in vivo gene transfer into skeletal muscle cells of different maturity. Hum Mol Genet 3: 579-584

2. Balasuriya UB, Heidner HW, Hedges JF, Williams JC, Davis NL, Johnston RE, MacLachlan NJ (2000) Expression of the two major envelope proteins of equine arteritis virus as a heterodimer is necessary for induction of neutralizing antibodies in mice immunized with recombinant Venezuelan equine encephalitis virus replicon particles. J Virol 74: 10623-10630

3. Callebaut P, Enjuanes L, Pensaert M (1996) An adenovirus recombinant expressing the spike glycoprotein of porcine respiratory coronavirus is immunogenic in swine. J Gen Virol 77 (Pt 2): 309-313

4. Cavanagh D (1997) Nidovirales: a new order comprising Coronaviridae and Arteriviridae. Arch Virol 142: 629-633

5. Chen Z, Li K, Plagemann PG (2000) Neuropathogenicity and sensitivity to antibody neutralization of lactate dehydrogenase-elevating virus are determined by 
polylactosaminoglycan chains on the primary envelope glycoprotein. Virology 266: 88-98

6. Chirnside ED, de Vries AA, Mumford JA, Rottier PJ (1995) Equine arteritis virusneutralizing antibody in the horse is induced by a determinant on the large envelope glycoprotein GL. J Gen Virol 76: 1989-1998

7. Corti O, Sabate O, Horellou P, Colin P, Dumas S, Buchet D, Buc-Caron MH, Mallet J (1999) A single adenovirus vector mediates doxycycline-controlled expression of tyrosine hydroxylase in brain grafts of human neural progenitors. Nat Biotechnol 17: 349-354

8. de Vries AA, Chirnside ED, Horzinek MC, Rottier PJ (1992) Structural proteins of equine arteritis virus. J Virol 66: 6294-6303

9. de Vries AA, Post SM, Raamsman MJ, Horzinek MC, Rottier PJ (1995) The two major envelope proteins of equine arteritis virus associate into disulfide-linked heterodimers. J Virol 69: 4668-4674

10. Dea S, Gagnon CA, Mardassi H, Pirzadeh B, Rogan D (2000) Current knowledge on the structural proteins of porcine reproductive and respiratory syndrome (PRRS) virus: comparison of the North American and European isolates. Arch Virol 145: 659-688

11. Dea S, Wilson L, Therrien D, Cornaglia E (2000) Competitive ELISA for detection of antibodies to porcine reproductive and respiratory syndrome virus using recombinant E. coli-expressed nucleocapsid protein as antigen. J Virol Methods 87: 109-122

12. Eloit M, Gilardi-Hebenstreit P, Toma B, Perricaudet M (1990) Construction of a defective adenovirus vector expressing the pseudorabies virus glycoprotein gp50 and its use as a live vaccine. J Gen Virol 71: 2425-2431

13. Faaberg KS, Even C, Palmer GA, Plagemann PG (1995) Disulfide bonds between two envelope proteins of lactate dehydrogenase-elevating virus are essential for viral infectivity. J Virol 69: 613-617

14. Gonin P, Oualikene W, Fournier A, Eloit M (1996) Comparison of the efficacy of replication-defective adenovirus and Nyvac poxvirus as vaccine vectors in mice. Vaccine 14: $1083-1087$

15. Gonin P, Pirzadeh B, Gagnon CA, Dea S (1999) Seroneutralization of porcine reproductive and respiratory syndrome virus correlates with antibody response to the GP5 major envelope glycoprotein. J Vet Diagn Invest 11: 20-26

16. Goyal SM (1993) Porcine reproductive and respiratory syndrome. J Vet Diagn Invest 5: 656-664

17. Graham FL, Prevec L (1992) Adenovirus-based expression vectors and recombinant vaccines. Biotechnology 20: 363-390

18. Jani A, Lochmuller H, Acsadi G, Simoneau M, Huard J, Garnier A, Karpati G, Massie B (1997) Generation, validation, and large scale production of adenoviral recombinants with large size inserts such as a $6.3 \mathrm{~kb}$ human dystrophin cDNA. J Virol Methods 64: $111-124$

19. Klausner RD, Donaldson JG, Lippincott-Schwartz J (1992) Brefeldin A: insights into the control of membrane traffic and organelle structure. J Cell Biol 116: 1071-1080

20. Kozak M (1987) At least six nucleotides preceding the AUG initiator codon enhance translation in mammalian cells. J Mol Biol 196: 947-950

21. Lemieux P, Guerin N, Paradis G, Proulx R, Chistyakova L, Kabanov A, Alakhov V (2000) A combination of poloxamers increases gene expression of plasmid DNA in skeletal muscle. Gene Ther 7: 986-991

22. Loemba HD, Mounir S, Mardassi H, Archambault D, Dea S (1996) Kinetics of humoral immune response to the major structural proteins of the porcine reproductive and respiratory syndrome virus. Arch Virol 141: 751-761 
23. Mardassi H, Athanassious R, Mounir S, Dea S (1994) Porcine reproductive and respiratory syndrome virus: morphological, biochemical and serological characteristics of Quebec isolates associated with acute and chronic outbreaks of porcine reproductive and respiratory syndrome. Can J Vet Res 58: 55-64

24. Mardassi H, Massie B, Dea S (1996) Intracellular synthesis, processing, and transport of proteins encoded by ORFs 5 to 7 of porcine reproductive and respiratory syndrome virus. Virology 221: 98-112

25. Massie B (1998) BMAdE1, a new complementing cell line for the large scale production of E1-deleted Adenovirus (Ad) vectors devoid of RCA (replication competent Ad). patent $5,891,6690$, U.S.

26. Massie B, Couture F, Lamoureux L, Mosser DD, Guilbault C, Jolicoeur P, Belanger F, Langelier Y (1998) Inducible overexpression of a toxic protein by an adenovirus vector with a tetracycline-regulatable expression cassette. J Virol 72: 2289-2296

27. Massie B, Mosser DD, Koutroumanis M, Vitté-Mony I, Lamoureux L, Couture F, Paquet L, Guilbault C, Dionne J, Chala D, Jolicoeur P, Langelier Y (1998) New adenovirus vectors for protein production and gene transfer. Cytotechnology 28: 53-64

28. Matthews DA, Cummings D, Evelegh C, Graham FL, Prevec L (1999) Development and use of a 293 cell line expressing lac repressor for the rescue of recombinant adenoviruses expressing high levels of rabies virus glycoprotein. J Gen Virol 80: 345-353

29. Meulenberg JJ, Hulst MM, de Meijer EJ, Moonen PL, den Besten A, de Kluyver EP, Wensvoort G, Moormann RJ (1993) Lelystad virus, the causative agent of porcine epidemic abortion and respiratory syndrome (PEARS), is related to LDV and EAV. Virology 192: 62-72

30. Meulenberg JJ, Petersen-den Besten A, De Kluyver EP, Moormann RJ, Schaaper WM, Wensvoort G (1995) Characterization of proteins encoded by ORFs 2 to 7 of Lelystad virus. Virology 206: 155-163

31. Mittal SK, Papp Z, Tikoo SK, Baca-Estrada ME, Yoo D, Benko M, Babiuk LA (1996) Induction of systemic and mucosal immune responses in cotton rats immunized with human adenovirus type 5 recombinants expressing the full and truncated forms of bovine herpesvirus type 1 glycoprotein gD. Virology 222: 299-309

32. Nelson EA, Christopher-Hennings J, Benfield DA (1994) Serum immune responses to the proteins of porcine reproductive and respiratory syndrome (PRRS) virus. J Vet Diagn Invest 6: 410-415

33. Pirzadeh B, Dea S (1997) Monoclonal antibodies to the ORF5 product of porcine reproductive and respiratory syndrome virus define linear neutralizing determinants. J Gen Virol 78: 1867-1873

34. Pirzadeh B, Dea S (1998) Immune response in pigs vaccinated with plasmid DNA encoding ORF5 of porcine reproductive and respiratory syndrome virus. J Gen Virol 79: 989-999

35. Pirzadeh B, Gagnon CA, Dea S (1998) Genomic and antigenic variations of porcine reproductive and respiratory syndrome virus major envelope GP5 glycoprotein. Can J Vet Res 62: 170-177

36. Rowland RR, Kervin R, Kuckleburg C, Sperlich A, Benfield DA (1999) The localization of porcine reproductive and respiratory syndrome virus nucleocapsid protein to the nucleolus of infected cells and identification of a potential nucleolar localization signal sequence. Virus Res 64: 1-12

37. Scudder P, Hanfland P, Uemura K, Feizi T (1984) Endo-beta-D-galactosidases of Bacteroides fragilis and Escherichia freundii hydrolyze linear but not branched oligosaccharide domains of glycolipids of the neolacto series. J Biol Chem 259: 6586-6592 
38. Sirinarumitr T, Zhang Y, Kluge JP, Halbur PG, Paul PS (1998) A pneumo-virulent United States isolate of porcine reproductive and respiratory syndrome virus induces apoptosis in bystander cells both in vitro and in vivo. J Gen Virol 79: 2989-2995

39. Snijder EJ, Meulenberg JJ (1998) The molecular biology of arteriviruses. J Gen Virol 79: 961-979

40. Suarez P, Diaz-Guerra M, Prieto C, Esteban M, Castro JM, Nieto A, Ortin J (1996) Open reading frame 5 of porcine reproductive and respiratory syndrome virus as a cause of virus-induced apoptosis. J Virol 70: 2876-2882

41. Sur JH, Doster AR, Christian JS, Galeota JA, Wills RW, Zimmerman JJ, Osorio FA (1997) Porcine reproductive and respiratory syndrome virus replicates in testicular germ cells, alters spermatogenesis, and induces germ cell death by apoptosis. J Virol 71: 9170-9179

42. Sur JH, Doster AR, Osorio FA (1998) Apoptosis induced in vivo during acute infection by porcine reproductive and respiratory syndrome virus. Vet Pathol 35: 506-514

43. Torres JM, Sanchez C, Sune C, Smerdou C, Prevec L, Graham F, Enjuanes L (1995) Induction of antibodies protecting against transmissible gastroenteritis coronavirus (TGEV) by recombinant adenovirus expressing TGEV spike protein. Virology 213: 503-516

44. Torres JM, Alonso C, Ortega A, Mittal S, Graham F, Enjuanes L (1996) Tropism of human adenovirus type 5-based vectors in swine and their ability to protect against transmissible gastroenteritis coronavirus. J Virol 70: 3770-3780

45. Tuboly T, Nagy E, Derbyshire JB (1993) Potential viral vectors for the stimulation of mucosal antibody responses against enteric viral antigens in pigs. Res Vet Sci 54: 345-350

46. Wu WH, Fang Y, Farwell R, Steffen-Bien M, Rowland RR, Christopher-Hennings J, Nelson EA (2001) A 10-kda structural protein of porcine reproductive and respiratory syndrome virus encoded by orf2b. Virology 287: 183-191

47. Xiang ZQ, Yang Y, Wilson JM, Ertl HC (1996) A replication-defective human adenovirus recombinant serves as a highly efficacious vaccine carrier. Virology 219: 220-227

Author's address: Dr. Carl A. Gagnon, INRS-Institut Armand-Frappier, Université du Québec, 531 boul. des Prairies, Laval, Québec, Canada, H7V 1B7; e-mail: Carl.Gagnon@inrsiaf.uquebec.ca 